Revista Destaques Acadêmicos, Lajeado, v. 10, n. 4, 2018. ISSN 2176-3070

DOI: http://dx.doi.org/10.22410/issn.2176-3070.v10i4a2018.2040

http://www.univates.br/revistas

\title{
PROPOSTAS METODOLÓGICAS PARA ENQUADRAMENTO DE RECURSOS HÍDRICOS: ESTUDO DE CASO DE UMA ANÁLISE DISTINTA PARA O ENQUADRAMENTO DE CORPOS HÍDRICOS URBANOS
}

\author{
Vrandrieli Jucieli Skovronski ${ }^{1}$, Adriana Paula Francieski ${ }^{1}$, \\ Saraiane Eluise Bender ${ }^{1}$, Cristiane Funghetto Fuzinatto ${ }^{2}$
}

\begin{abstract}
Resumo: As propostas metodológicas para os corpos hídricos e seus respectivos enquadramentos são determinadas pelo nível de qualidade da água e para os usos em que o corpo hídrico será destinado. O embasamento para o enquadramento é realizado a partir de Resoluções e Leis de âmbito ambiental, visando aplicar instrumentos de gestão e planejamento dos corpos hídricos levando-se em consideração os aspectos qualitativos, quantitativos e outros que afetem os recursos hídricos. O processo de enquadramento dos recursos hídricos, e em especial as consultas públicas possibilitam uma proximidade entre o sistema de gestão dos recursos hídricos e a população da bacia, pois através destas podem ser modificadas, com base nos usos preponderantes de água para cada trecho dos corpos hídricos da bacia, por isso da necessidade de divulgação, além de abrir espaços para discussões com a sociedade a respeito de questões ambientais. A discussão do processo do enquadramento dos recursos hídricos deve proporcionar o exercício da representatividade e contribuir para o fortalecimento do Comitê de Bacia, no seu papel de gestor das águas. Sendo assim, é necessário que se reflita e se aprofunde as metodologias participativas, para que a participação pública no processo de enquadramento seja satisfatória.
\end{abstract}

Palavras-chave: Desenvolvimento sustentável. Gestão dos Recursos Hídricos. População participativa.

1 Acadêmicas do Curso de Engenharia Ambiental e Sanitária pela Universidade Federal da Fronteira Sul - UFFS, campus Erechim,RS - E-mail: vrandryskovronski@gmail.com

2 Doutora em Engenharia Ambiental, docente do curso de Graduação em Engenharia Ambiental e Sanitária, Universidade Federal da Fronteira Sul, campus Erechim, RS - E-mail: cristiane. fuzinatto@uffs.edu.br 


\section{INTRODUÇÃO}

O gerenciamento dos recursos hídricos está em constante evolução devido à crescente demanda de água. Observa-se que a escassez e os conflitos envolvendo os usos múltiplos da água são cada vez mais constantes, uma vez que a disponibilidade hídrica é um fator fundamental ao desenvolvimento econômico, social e cultural de uma região. As atividades antrópicas têm afetado a quantidade e a qualidade da água, o que por sua vez compromete a garantia de aproveitamento, presente e futuro, dos recursos hídricos, baseados no conceito de sustentabilidade hídrica (BRITES, 2010).

A Política Nacional de Recursos Hídricos, lei 9433/97 traz em seu Art. $2^{\circ}$ que são objetivos da Política Nacional de Recursos Hídricos: "assegurar à atual e às futuras gerações a disponibilidade de água, em padrões de qualidade adequados aos respectivos usos; a utilização racional e integrada dos recursos hídricos, com vistas ao desenvolvimento sustentável".

$\mathrm{O}$ enquadramento dos recursos hídricos trata sobre a determinação do nível de qualidade da água a ser obtido ou conservado em um segmento de corpo d'água ao longo do tempo (ANA, 2007). O enquadramento procura "assegurar às águas qualidade compatível com os usos mais exigentes a que forem destinadas" e a "diminuir os custos de combate à poluição das águas, mediante ações preventivas permanentes" (Art. $9^{\circ}$, lei no 9.433, de 1997).

A Resolução CONAMA 357/2005 dispõe sobre a classificação dos corpos d'água e diretrizes ambientais para o seu enquadramento, o Art. $3^{\circ}$ dispõem sobre as águas doces, salobras e salinas do Território Nacional e como são classificadas, segundo a qualidade requerida para os seus usos preponderantes, em classes de qualidade. $\mathrm{O}$ Art. $7^{\circ}$ traz os padrões de qualidade das águas determinados na respectiva Resolução e estabelecem limites individuais para cada substância em cada classe. Já a Resolução n ${ }^{\circ}$ 91, de 05 de novembro de 2008 dispõe sobre procedimentos gerais para o enquadramento dos corpos d' água superficiais e subterrâneos.

$\mathrm{O}$ enquadramento dos recursos hídricos deve ser visto como um instrumento de planejamento e não como uma simples classificação, pois baseia-se nos níveis de qualidade que o corpo d'água deveria possuir ou manter para atender as necessidades de uma determinada comunidade, e não somente seu estado atual de conservação. A classe do enquadramento de um recurso hídrico é definida através de um pacto acordado pela sociedade, sendo que este ocorre por meio de discussões e análises dentro do Sistema Nacional de Gerenciamento de Recursos Hídricos (SINGREH) (ANA, 2007).

$\mathrm{O}$ enquadramento é referência para significativos instrumentos de gestão de recursos hídricos, como outorga, cobrança, planos de bacia, sendo também referência para instrumentos de gestão ambiental como licenciamento e monitoramento. O enquadramento é uma importante ligação entre o Sistema 
Nacional de Gerenciamento de Recursos Hídricos e o Sistema Nacional de Meio Ambiente (SISNAMA) (ANA, 2007).

Desta maneira, o presente estudo buscou avaliar de que maneira está ocorrendo no Brasil o enquadramento de recursos hídricos, através do entendimento do que se trata o enquadramento, dos aspectos quantitativos, qualitativos e dos aspectos intervenientes da qualidade da água, além da verificação de como decorrem às propostas metodológicas de enquadramento e finalizando com a análise do estudo de caso intitulado de Uma Análise Distinta para o Enquadramento de Corpos Hídricos Urbanos: Estudo de Caso da Bacia do Alto Iguaçu de Camila de Carvalho Almeida de Bitencourt e Cristovão Vicente Scapulatempo Fernandes.

\section{ENQUADRAMENTO DE RECURSOS HÍDRICOS}

Em âmbito federal, a classificação das águas interiores segundo seus usos preponderantes foi instituída por meio da Portaria GM 013 do Ministério do Interior, de 15 de janeiro de 1976. Posteriormente, em decorrência da execução da Política Nacional do Meio Ambiente, a citada Portaria foi aperfeiçoada, sendo substituída pela Resolução número 20 de 18 de junho de 1986, do Conselho Nacional de Meio Ambiente - CONAMA relativa à classificação das águas doces, salobras e salinas no Território Nacional (IGAM, 2010).

Deste modo, a Resolução CONAMA 357/05 classifica as águas brasileiras, conforme sua salinidade, em: águas doces (salinidade inferior ou igual a $0,5 \%$ ), salobras (salinidade entre $0,5 \%$ e $30 \%$ ) e salinas (salinidade superior a 30\%). No que refere-se às águas doces, a Resolução menciona a classificação de cinco classes: classe especial, classe 1, classe 2, classe 3 e classe 4. A Figura 1 apresenta por meio de um esquema, de forma resumida, as classes definidas pela Resolução para as águas doces, além dos usos a que são destinadas.

Os usos preponderantes a serem ponderados são os previstos nas classes de enquadramento pela Resolução CONAMA 357/05: abastecimento para consumo humano; preservação do equilíbrio natural das comunidades aquáticas, preservação dos ambientes aquáticos em unidades de conservação e proteção integral; proteção das comunidades aquáticas; recreação de contato primário e secundário; irrigação; aquicultura e pesca; dessedentação de animais; navegação, harmonia paisagística, além da verificação de outros usos como o industrial, a mineração e a produção hidroelétrica, caso sejam pertinentes para a realidade da bacia hidrográfica (BRASIL, 2005). 
Figura 1 - Classes de enquadramento das Águas Doces e seus respectivos usos.

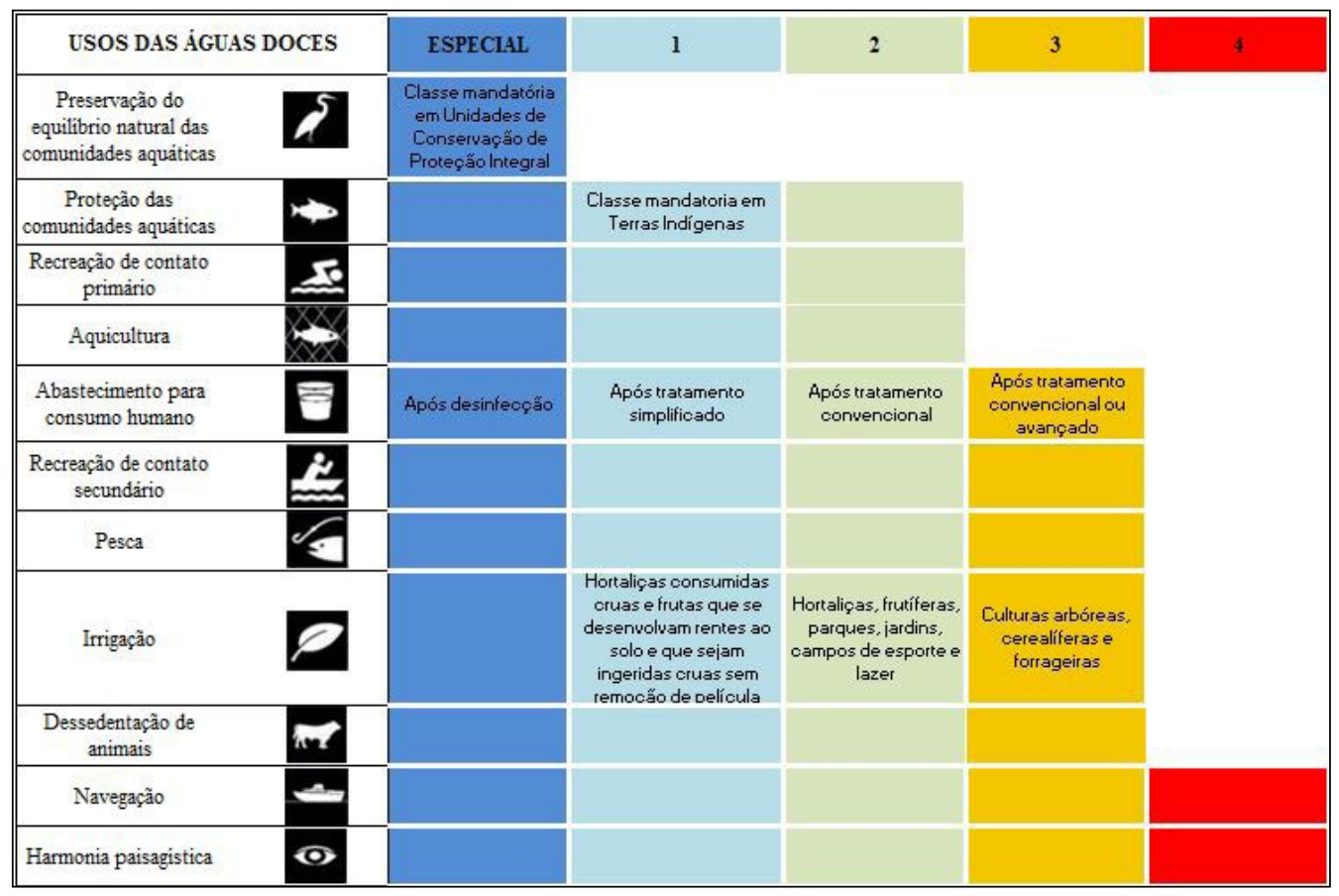

Fonte: Adaptado de ANA (2012).

O enquadramento dos corpos d'água é considerado o único instrumento de gestão de recursos hídricos que compatibiliza a Política de Meio Ambiente com a Política de Recursos Hídricos, o que colaborou para a aprovação da Resolução CONAMA 357/05, que dispõe sobre a classificação dos corpos d'água e diretrizes ambientais para o seu enquadramento, bem como estabelece as condições e padrões de lançamento de efluentes, este último substituído pela Resolução 430/2011.

O enquadramento de corpos d'água é um dos instrumentos da PNRH de extrema importância para o gerenciamento de recursos hídricos, principalmente no que tange a gestão integrada de quantidade e qualidade dos corpos hídricos (PORTO, 2002). Este instrumento também assegurar às águas qualidade compatível com os usos mais exigentes a que forem destinadas, e objetiva diminuir os custos de combate à poluição por meio de ações preventivas permanentes que assegurem a qualidade dos recursos hídricos, levando em consideração a saúde e o bem-estar humano, bem como o equilíbrio ecológico e aquático (BRITES, 2010).

Este instrumento não baseia-se apenas na qualidade das águas dos corpos hídricos a serem enquadrados no estado atual, mas também nos níveis 
de qualidade que um corpo hídrico deveria ter para atender as demandas definidas pela sociedade (LEEUWESTEIN e MONTEIRO, 2000).

Embora o enquadramento dos corpos hídricos seja reconhecido na Resolução CONAMA 357/05 como um "sistema de planejamento que exige metas progressivas intermediárias e finais", não está explícita a obrigatoriedade de melhoria constante da qualidade da água, uma vez que existe a possibilidade de enquadramento final em classes com determinado grau de degradação (PESSÔA, 2013).

Sendo assim, faz-se necessário trazer à tona a discussão de que o enquadramento não reflete apenas nos aspectos estritamente relacionados à qualidade da água. Uma vez que o enquadramento relaciona-se a usos da água por vezes conflitantes, este assume um papel de pacto social, os conflitos são discutidos e expressos em metas de qualidade da água. Está discussão ocorre no âmbito do Sistema Nacional de Gerenciamento dos Recursos Hídricos (SINGREH), e a aprovação final acontece no respectivo Conselho de Recursos Hídricos, a depender do domínio do rio em questão (BRASIL, 2007).

Da mesma forma, o enquadramento assume papel importante no que refere-se à saúde pública, uma vez que associa os usos possíveis para cada classe de acordo com o grau de qualidade. $\mathrm{O}$ enquadramento também pode ser relacionado com o planejamento e uso do solo, uma vez que, baseado nos padrões de qualidade estabelecidos para determinada classe, empreendimentos potencialmente poluidores podem ser impedidos de instalar-se em determinados locais (PESSÔA, 2013).

\section{1 Aspectos quantitativo dos recursos hídricos}

Para um bom gerenciamento do potencial hídrico de uma região é necessário compreender as sazonalidades, vazões e o comportamento dos corpos hídricos. Neste sentido, a estimativa de disponibilidade hídrica da bacia hidrográfica é fundamental para a elaboração do diagnóstico para o enquadramento do corpo hídrico e com estas informações pode-se obter um adequado planejamento do uso e gestão compartilhada dos recursos hídricos, minimizando assim, os conflitos entre os usuários desta região (SILVA, 2010; SOARES et al., 2010).

A estimativa da disponibilidade hídrica determina a parcela da vazão de um corpo hídrico que pode ser usada pela população para o desenvolvimento, sem que afete o meio ambiente aquático. As ferramentas mais utilizadas para determinar a disponibilidade hídrica de uma bacia são a curva de permanência, hidrograma e a curva de probabilidade de vazões médias e mínimas (CRUZ e SILVEIRA, 2007; SOARES et al., 2010) . Desta maneira, é também necessário realizar a quantificação hídrica da bacia com a utilização de uma série histórica de vazões e dados fluviométricos. Entretanto, no Brasil é difícil realizar o monitoramento de bacias de pequeno porte, devido a rede hidrometeorológica 
atender as grandes bacias hidrográficas (maiores que $500 \mathrm{~km}^{2}$ ), com isso acaba por dificultar a obtenção de dados hidrológicos (SOARES et al., 2010; SANTOS e HERANDES, 2013).

\subsection{Aspectos qualitativo dos recursos hídricos}

A análise das propriedades biológicas, física e química da água gera subsídios necessários à caracterização dos corpos hídricos de bacias hidrográficas. Desta maneira, a interpretação e análise das variáveis da qualidade da água monitorada indica como está a condição de uso do solo e das atividades humanas na bacia. Com isto, é de fundamental importância a avaliação da qualidade da água para o gerenciamento integrado de recursos hídricos (GONÇALVES et al, 2012).

Neste sentido, o intuito do programa de monitoramento qualitativo presume o levantamento sistematizado de dados de qualidade da água em pontos de amostragem pré-estabelecidos para acompanhar a evolução das condições da qualidade da água durante o tempo, de modo, a gerar uma série temporal de dados (MOREIRA, 2007). Ter-se água com qualidade adequada é importante para a manutenção dos ecossistemas aquáticos e para as diversas atividades humanas, das quais pode-se destacar, o abastecimento, o uso industrial, a irrigação, a aquicultura, a dessedentação animal, dentre outros (ANA, 2012).

Os contaminantes químicos presentes nos corpos hídricos superficiais podem ser determinados em termos de concentração e parâmetros químicos, físicos e biológicos. Sendo que os principais poluidores das águas são: matéria orgânica biodegradável, nutrientes, sólidos em suspensão, organismos patogênicos (como coliformes), matéria orgânica não biodegradável (como agrotóxicos, detergentes, etc.), sólidos inorgânicos dissolvidos e metais. Estes poluentes podem vir de áreas urbanas e rurais, como de esgotos domésticos, efluentes agrícolas e de criação de animais, despejos industriais e do escoamento superficial (VON SPERLING, 2005).

São utilizados padrões de qualidade da água para regulamentar os níveis de qualidade a se manter ou obter de um corpo d'água, de forma a este estar de acordo com os usos a que se destinam. A utilização de padrões de qualidade tem o propósito de manter a qualidade do curso d'água ou definir a meta a ser atingida para o mesmo e também de servir como base para definir os níveis de tratamento a serem adotados na bacia, de forma que os poluentes lançados não modifiquem as características do corpo hídrico que foram estabelecidas pelo padrão (PORTO et al., 1991).

\subsection{Aspectos intervenientes na qualidade da água}

As características do solo e seus diferentes usos influenciam diretamente a qualidade da água das bacias hidrográficas. De acordo com resultados 
apresentados por Vanzela (2010), áreas ocupadas por matas favorecem o aumento da vazão específica em virtude da maior cobertura, estabilidade e capacidade de infiltração de água no solo. Promovendo assim, a redução da intensidade do escoamento superficial, o que contribui para a melhoria da qualidade da água. De maneira geral, as áreas habitadas (área urbana e moradias rurais), agricultadas (culturas perenes, perenes irrigadas e anuais) e as matas degradadas, contribuem para a redução da vazão específica e da qualidade da água em função da alteração na intensidade do escoamento superficial.

O relevo de uma bacia hidrográfica tem grande influência sobre os fatores meteorológicos e hidrológicos, pois a velocidade do escoamento superficial é determinada pela declividade do terreno, enquanto que a temperatura, a precipitação e a evaporação são funções da altitude da bacia (MOSCA, 2003).

A Pedologia de uma região busca identificar, descrever e mapear os diversos tipos de solo que existem. Após a precipitação, uma parte da água flui sobre as superfícies sólidas para os rios, sendo carreadas até os oceanos, em diferentes escalas temporais, e a outra parte evapora, retornando para atmosfera. Porém o que resta dessa água infiltra-se nos solos exercendo papel crucial na manutenção dos processos físico-químicos e biológicos de grande importância para vida vegetal, bem como na formação de reservatórios subterrâneos, realimentando, lenta ou rapidamente, as fontes e os cursos de águas superficiais (GONÇALVES, 2012).

\section{PROCEDIMENTOS PARA O ENQUADRAMENTO NO BRASIL}

O desenvolvimento do enquadramento deve estar em conformidade com o Plano de Recurso Hídricos da Bacia Hidrográfica e os Planos de Recursos Hídricos Estadual ou Distrital, Regional e Nacional, e caso estes sejam insuficiente ou não existam, deve-se levar em consideração estudos específicos propostos e aprovados pelas instituições competentes dos sistemas de gerenciamento de recursos hídricos (PESSÔA, 2013). No Brasil, o enquadramento é elaborado com base na Resolução do Conselho Nacional de Recursos Hídricos 91/05, sendo que o enquadramento é dividido em três etapas: elaboração da proposta, seleção e aprovação, e efetivação e avaliação.

\subsection{Elaboração da proposta de enquadramento}

A Agência Nacional das Águas (ANA) é quem tem a função de propor aos Comitês de Bacia o enquadramento dos recursos hídricos em classes, levando em consideração o que está disposto nas legislações de recursos hídricos e ambiental, cumprindo os procedimentos expostos na Resolução do Conselho Nacional de Recursos Hídricos (CNRH) 91/08. Caso não exista a Agência de Bacia, quem passa a ter a responsabilidade de realizar a proposição do enquadramento ao Comitê de Bacia é o órgão gestor dos recursos hídricos, em articulação com o órgão ambiental (PESSÔA, 2013). 
Sobre a Resolução CNRH 91/08, esta dispõe sobre o conteúdo mínimo que uma proposta de enquadramento deva ter, considerando o diagnóstico, prognóstico, proposta de metas relativas às alternativas de enquadramento e 0 programa para efetivação.

A etapa do diagnóstico consiste no reconhecimento da bacia hidrográfica onde está localizado o corpo hídrico que será enquadrado, identificação das potencialidades, limitações e riscos relativos aos recursos hídricos na região. A Resolução CNRH 91/08 menciona o conteúdo mínimo de caracterização geral da bacia hidrográfica e do uso e ocupação do solo; a identificação e localização dos usos e interferências que alterem o regime, a quantidade ou a qualidade da água; identificação, localização e quantificação das cargas das fontes poluidoras pontuais e difusas atuais; disponibilidade, demanda e condições de qualidade das águas superficiais e subterrâneas; potencialidade e qualidade natural das águas subterrâneas; mapeamento das áreas vulneráveis e suscetíveis a riscos e efeitos de contaminação, poluição, escassez de água, conflitos de uso, erosão, cheias, etc.; identificação das áreas reguladas por legislação específica; arcabouço legal e institucional pertinente; políticas, planos e programas locais e regionais existentes; capacidade de investimento em ações de gestão de recursos hídricos; caracterização socioeconômica da bacia hidrográfica.

Na fase do prognóstico é realizada a avalição do impacto nos corpos hídricos em decorrência da implementação de programas e planos de desenvolvimento identificados para a região na fase do diagnóstico. A Resolução CNRH 91/08 cita que devem ser analisados os cenários em curto, médio e longo prazo, de forma a realizar projeções considerando a disponibilidade e demanda hídrica, potencialidade, condições de quantidade e qualidade dos corpos hídricos, cargas poluidoras existentes e usos pretendidos para os recursos hídricos.

A fase de proposta de metas relativas às alternativas de enquadramento, após definido os usos pretendidos do recurso hídrico, deve-se estabelecer metas de qualidade da água considerando os cenários de curto, médio e longo prazo da fase anterior. Essas metas devem ser definidas com base no conjunto de dados de qualidade da água, selecionados conforme os usos pretensos e considerando o diagnóstico e prognóstico realizados anteriormente. $\mathrm{O}$ conjunto de parâmetros selecionados servem de referencial para a escolha de ações prioritárias de prevenção, controle e recuperação da qualidade da água. Para o alcance da meta final devem ser feitas metas intermediárias da qualidade da água desejada a ser alcançada.

De acordo com Pessôa (2013) a última fase da etapa da proposta de conteúdo do enquadramento baseia-se nos programas de efetivação, que consiste em um programa de propostas de ações de gestão e seus prazos de execução, os instrumentos de compromisso e os planos de investimentos. Sendo recomendado pela Resolução CNRH 91/08 que o programa de efetivação contenha: 
- Recomendações para os órgãos gestores de recursos hídricos e de meio ambiente que desempenham a implementação, integração ou adequação de seus instrumentos de gestão, conforme as metas estabelecidas, especialmente o licenciamento ambiental e a outorga de direito de uso de recursos hídricos;

- Recomendações de ações preventivas, educativas e corretivas para mobilização social e de gestão, de forma a identificar os custos e fontes de financiamento;

- Recomendações para os agentes privados e públicos envolvidos, para facilitar o alcance das metas e também os mecanismos de formalização, apontando as atribuições e compromissos que assumiram;

- Apresentação de propostas para os poderes públicos municipal, estadual e federal para adequação dos programas, planos e projetos de desenvolvimento e também dos planos de uso e ocupação do solo às metas definidas na proposta de enquadramento;

- Recomendações e subsídios técnicos para a atuação dos comitês de bacia hidrográfica.

\subsection{Seleção e aprovação da proposta de enquadramento}

O Comitê de Bacia deve elaborar discussões sobre o enquadramento de água proposto, efetuando modificações que forem essenciais, quando aprovado e encaminhar para o Conselho de Recursos Hídricos para realizar a deliberação. Caso não tenha instituído o Comitê de Bacia, a proposta do enquadramento do recurso hídrico deverá ser enviada diretamente para o Conselho de Recursos Hídricos, em que este realizará a análise e deliberação desta (PESSÔA, 2013).

\subsection{Efetivação e avaliação}

Posteriormente a aprovação do enquadramento do corpo hídrico, os órgãos ambientais e gestores de recursos hídricos deverão monitorar a qualidade da água, de modo a controlar, fiscalizar e avaliar o cumprimento das metas propostas no enquadramento. Para isto, deve-se encaminhar a cada dois anos o relatório técnico para os Comitês de Bacia e o Conselho de Recursos Hídricos examinando os corpos hídricos que não atingiram a metas propostas e também acerca das causas possíveis desse não atingimento de metas (PESSÔA, 2013).

\section{ESTUDO DE CASO}

O estudo de caso intitulado de: Uma Análise Distinta Para o Enquadramento de Corpos Hídricos Urbanos: Estudo de Caso da Bacia do Alto Iguaçu traz que apesar de o enquadramento ter como objetivo prevenir a 
poluição hídrica e garantir a qualidade da água compatível com os usos mais exigentes, o que se percebe é que a Resolução CONAMA 357/05 não inclui alguns indicadores de qualidade da água de forma competente, tão pouco uma reflexão sobre a referência hidrológica necessária para a sua compreensão. Outro ponto é que o enquadramento não tem uma metodologia detalhada definida, dessa forma, em cada bacia aplica-se um método que acredita-se ser o mais conveniente, mas isso nem sempre é a melhor opção do ponto de vista do corpo hídrico, mas sim, das partes interessadas no uso da água.

Uma maneira de avaliar grandes conjuntos de dados é a aplicação de métodos estatísticos, na prática, é a análise simultânea do conjunto de informações, a aplicação de técnicas estatísticas multivariadas torna-se o mais indicado, uma vez que esse método se molda para este tipo de análise. $\mathrm{O}$ objetivo do estudo foi a avaliação da dinâmica de concentração e carga poluente associados aos resultados obtidos nas técnicas de estatística multivariada na Bacia do Alto Iguaçu, localizada na Região Metropolitana de Curitiba, através de um monitoramento quali-quantitativo que está sendo realizado desde 2005.

O estudo de caso foi incrementado a partir da dinâmica de uso e ocupação do solo na bacia do Alto Iguaçu, na região metropolitana de Curitiba. A bacia do Alto Iguaçu tem uma extensão de aproximadamente $90 \mathrm{~km}$, com uma área de drenagem de cerca de $2.800 \mathrm{~km}^{2}$. A população que vive nesta bacia conta com 3 milhões de habitantes, que são distribuídos em 14 municípios. A região é altamente urbanizada e vem passando por um processo de ocupação irregular de áreas de mananciais e várzeas, especialmente na margem direita do rio Iguaçu.

Para o monitoramento da qualidade da água utilizou-se dados de 35 campanhas de monitoramento, que continuou a ser realizado após o termino do projeto. Os parâmetros físico-químicos determinados in situ através de sensores foram: oxigênio dissolvido $(\mathrm{OD}, \mathrm{em} \mathrm{mg} / \mathrm{L})$, temperatura da água $\left({ }^{\circ} \mathrm{C}\right)$, condutividade elétrica $(\mu \mathrm{S} / \mathrm{cm}), \mathrm{pH}$ e turbidez (NTU). Amostras de água foram coletadas para posterior análise dos seguintes parâmetros de qualidade da água: demanda bioquímica de oxigênio (DBO), demanda química de oxigênio (DQO), nitrogênio orgânico (N_org), nitrogênio amoniacal (N_NH3) nitrito, nitrato, fósforo total, sólidos sedimentáveis, sólidos suspensos totais, sólidos dissolvidos totais e carbono orgânico total (COT).

Como métodos de análise estatística foram realizadas três técnicas de estatística multivariada: a análise de componentes principais (ACP) utilizada para reduzir a dimensão dos dados com muitas variáveis inter-relacionadas criando variáveis mais representativas, a análise fatorial (AF) que também tem o objetivo de diminuir o número de variáveis relacionadas criando fatores comuns e a análise de agrupamentos (AA) que agrupa em um mesmo conjunto variáveis semelhantes. Para isto, utilizou-se um programa livre e gratuito para as análises estatísticas e gráficas sendo o software R: A language and environment for statistical. Essas técnicas foram aplicadas aos dados de concentração e de 
carga referentes à Bacia do Alto Iguaçu a partir de uma matriz contendo os dados de todos os pontos de monitoramento nas linhas e os parâmetros de qualidade da água nas colunas.

Estes métodos têm por objetivo o enquadramento e o estabelecimento do nível de qualidade da água no ponto de análise. Como resultados nos parâmetros analisados, tanto para concentração quanto para carga as variâncias observadas foram de ordem de grandeza bem diferentes, por isso, as técnicas multivariadas foram aplicadas a partir da matriz de correlação das variáveis originais. Obtiveram-se mais correlações significativas $(\geq 7,0)$ para os dados de carga do que para concentração, e em comum obteve-se maiores correlações entre nitrogênio amoniacal e nitrogênio total.

No método de ACP utilizou-se o Critério de Kaiser para definir o número de componente a serem reduzidas, assim, observou-se como parâmetros importantes para concentração a $\mathrm{DBO}$, a $\mathrm{DQO}$, o nitrogênio amoniacal e o total, já para carga encontrou-se 10 variáveis (DBO, DQO, COT, SDT, SST, N_NH ${ }_{3}^{\prime}$ N_org, nitrito, nitrogênio total e vazão). Cabe destacar que os parâmetros encontrados estão ligados principalmente à degradação da matéria orgânica, aos sólidos e ao nitrogênio, portanto, a parâmetros que refletem de maneira direta as fontes de poluição ao longo da bacia.

No método de Análise Fatorial foi necessário analisar se o conjunto de dados continha uma distribuição normal e para isso foi utilizada a observação do gráfico de distribuição Qui-Quadrado dos dados. Neste método os fatores mais importantes foram o Nitrogênio amoniacal e o total como fator 1, a turbidez como fator 2 , a condutividade e o $\mathrm{pH}$ como fator 3 . Sendo estes fatores responsáveis por explicar $58 \%$ da variância da amostra com alguns parâmetros como: $\mathrm{DBO}, \mathrm{SST}$, condutividade, $\mathrm{pH}$, nitrogênio amoniacal, nitrogênio orgânico, nitrogênio total e fósforo.

Para o método de análise de agrupamento utilizou-se dados de coletas que continham valores e resultados atípicos, e na análise de carga do rio observou-se o esperado que com a alta vazão do rio os padrões de qualidade da água são melhores e quando tem-se uma baixa vazão do rio a qualidade do corpo hídrico diminui. Para esta análise fez-se necessário a separação do dendograma obtido em três grupos para melhor avaliação.

Deste modo, concluiu-se que a maioria das coletas do primeiro grupo possuía vazão maior do que a registrada geralmente no local de monitoramento, e no segundo grupo a maioria das coletas possuíam vazões menores que o normal e resultando numa maior concentração de DBO e COT na aplicação da AA. Com isto, constatou-se que as diferentes observações decorrentes da análise de carga e concentração para aplicação de técnicas de estatística multivariada para a avaliação da qualidade da água dos corpos hídricos é complexa e a definição da classe do rio analisando somente as concentrações não é o método mais adequado para se aplicar. Mesmo que a Resolução CONAMA 357/05 estabeleça valores máximos ou mínimos de concentração 
de vários parâmetros, no enquadramento a única variável analisada é a DBO. No entanto neste estudo a DBO e o OD não foram considerados como os de maior peso e sim as frações de nitrogênio, principalmente a forma amoniacal, demonstrando novamente que determinados equívocos têm sido gerados por meio de processos de enquadramento demasiadamente simplificados ou até mesmo generalizados para diferentes regiões e bacias.

\section{CONSIDERAÇÕES FINAIS}

Ainda que o instrumento de enquadramento dos recursos hídricos exista no Brasil desde o final da década de 70 na esfera federal, a sua implementação ainda é muito pequena, tanto para os corpos d'água estaduais quanto os federais (ANA, 2007). Mesmo entre as bacias enquadradas, diversas precisam de atualizações, pois foram enquadradas de acordo com sistemas de classificação que atualmente foram substituídos por legislações mais recentes.

Os principais motivos que levam as situações descritas acima são, o desconhecimento deste instrumento, a preferência de aplicação de outros instrumentos de gestão, em função dos instrumentos de planejamento, além das dificuldades metodológicas para sua aplicação.

O enquadramento dos corpos d'água tem papel importante no novo contexto de gestão da qualidade da água no nosso país, pois trata-se de um instrumento de planejamento que tem conexão com aspectos tanto da gestão dos recursos hídricos quanto da gestão ambiental. A determinação do enquadramento dos recursos hídricos deve ser tomada na esfera do SINGREH da Bacia Hidrográfica. Isso se deve devido ao fato de que o enquadramento deve refletir as expectativas da comunidade a respeito da qualidade da água e, assim, definir o nível de investimento fundamental para que o objetivo de qualidade da água seja satisfeito.

Em outras palavras, o processo de enquadramento de corpos d'água deve ter a participação da comunidade para legitimar as metas estabelecidas, deste modo, é importante que durante o diagnóstico sejam examinadas instituições públicas e privadas que atuam nas áreas de meio ambiente e de recursos hídricos da bacia, para que assim, obtenham-se conhecimentos para constatar os prováveis conflitos de uso. O processo de enquadramento dos recursos hídricos, e em especial as consultas públicas possibilitam uma proximidade entre o sistema de gestão dos recursos hídricos e a população da bacia, pois a partir dai podem ser identificados, com base nos usos preponderantes da água, os usos desejados de água para cada trecho dos corpos d'água da bacia, por isso da necessidade de divulgação, para que as pessoas possam também exercer sua cidadania a partir do momento em que escolhem a água que queremos ter no futuro, além de abrir espaço para discussões com a sociedade sobre questões ambientais. 
A discussão do processo do enquadramento dos recursos hídricos deve ser possibilitar o crescimento do Comitê, pois proporciona o exercício da representatividade e pode contribuir para o fortalecimento do Comitê de Bacia, no seu papel de gestor das águas de sua bacia. Sendo assim, é necessário que se reflita e se aprofunde as metodologias participativas, para que a participação pública no processo de enquadramento seja satisfatória, e que os participantes possam se apropriar do conhecimento deste processo.

\section{REFERÊNCIAS}

AGÊNCIA NACIONAL DE ÁGUAS - ANA, Panorama do Enquadramento dos Corpo d'água no Brasil. Cadernos de Recursos Hídricos. Brasília: ANA, 2007.

AGÊNCIA NACIONAL DE ÁGUAS - ANA, Planos de recursos hídricos e enquadramento dos corpos de água. Cadernos de Capacitação em Recursos Hídricos n. 5. Brasília: ANA, 2013.

BITENCOURT, C. C. A.; FERNANDES, C. V. S. Uma análise distinta para o enquadramento de corpos hídricos urbanos: estudo de caso da bacia do Alto Iguaçu. XXI Simpósio Brasileiro de Recursos Hídricos. Brasília, 2015.

BREHM, F. A.; FILIPPE, T.C.; AZEVEDO, J. C. R.; FERNANDES, C. V. S. Determinação de fármacos no Rio Iguaçu. XXI Simpósio Brasileiro de Recursos Hídricos. Brasília, 2015.

BRITES, A. P. Z. Enquadramento dos corpos de água através de metas progressivas: probabilidade de ocorrência e custos de despoluição hídrica. 2010. 174 f. Tese (Doutorado) - Curso de Engenharia Hidráulica, Escola Politécnica da Universidade de São Paulo, São Paulo, 2010.

BRASIL. Ministério do Meio Ambiente. Secretaria de Recursos Hídricos. Política Nacional de Recursos Hídricos. Lei n 9.433, de 8 de janeiro de 1997. Brasília, 1997.

BRASIL. Ministério do Meio Ambiente. Conselho Nacional do Meio Ambiente. Resolução CONAMA n ${ }^{\circ}$ 357, de 17 de março de 2005. Brasília, 2005.

BRASIL. Lei no 11445 de 5 de janeiro de 2007. Brasília, DF, 2007.

CONSELHO NACIONAL DE RECURSOS HÍDRICOS - CNRH, Resolução CNRH n ${ }^{\circ}$ 91 de 5 de novembro de 2008. Brasília, DF, 2008.

GONÇALVES, J.C.S.I et al. Avaliação espaço-temporal da qualidade da água e simulação de autodepuração na bacia hidrográfica do córrego São Simão, SP. Revista Ambiente \& Água - 93 An Interdisciplinary Journal of Applied Science: v. 7, n.3, 2012. 
INSTITUTO MINEIRO DE GESTÃO DAS ÁGUAS - IGAM. Plano Integrado de Recursos Hídricos da Bacia do Rio Doce e Planos de Ações de Recursos Hídricos. Belo Horizonte: 2010.

LEEUWESTEIN, J. M.; MONTEIRO, R. A. Procedimentos técnicos para enquadramento de corpos de água - Documento orientativo. Ministério do Meio Ambiente. Secretaria de Recursos Hídricos. Diretoria de Programa de Implementação. Brasília, 2000.

MOSCA, A. A. O. Caracterização hidrológica de duas microbacias visando a identificação de indicadores hidrológicos para o monitoramento ambiental do manejo de florestas plantadas. Dissertação. Universidade Estadual Paulista, 2003.

PORTO, M. F. A. A Evolução da Gestão dos Recursos Hídricos no Brasil. In: Agência Nacional de Águas. (Org.). A Evolução da Gestão dos Recursos Hídricos no Brasil. Brasília: Agência Nacional de Águas, 2002.

PORTO, R.L.L.; BRANCO, S.M.; CLEARY, R.W.; COIMBRA, R.M.; EIGER, S.; LUCA, S.J.; NOGUEIRA, V.P.Q.; PORTO, M.F.A. Hidrologia Ambiental. 3 ed. Edusp, São Paulo, 414p., 1991

VANZELA, L. S.; HERNANDEZ, F. B. T.; FRANCO, R. A. M. Influência do uso e ocupação do solo nos recursos hídricos do córrego Três Barras, Marinópolis. Revista Brasileira de Engenharia Agrícola e Ambiental. Campina Grande, v. 14, n. 1, p. 55-64, 2010.

VON SPERLING, M. Introdução à qualidade das águas e ao tratamento de esgotos. v.1, Belo Horizonte, 2005. 